\title{
Dad Rising? Playing the Father in Post-Apocalyptic Survival Horror Games
}

\author{
Michael Fuchs and Klaus Rieser
}

\begin{abstract}
Accepted manuscript of a chapter in Gender in Contemporary Horror in Comics, Games and Transmedia, edited by Robert Shail, Samantha Holland, and Steven Gerrard (Bingley, UK: Emerald Publishing, 2019), 69-80, DOI: 10.1108/978-1-78769107-020191008. Accepted manuscript published Green Open Access in accordance with publisher's OA policies.
\end{abstract}

In Dead Rising 2 (Blue Castle Games, 2010), former motocross rider Chuck Greene finds himself in the midst of a zombie outbreak. Five years prior, in another epidemic, Chuck's wife was killed and his daughter Katey bitten by one of the undead. The zombie infection cannot be cured, but it can be stopped from spreading in the victim's body by a drug called Zombrex. Katey needs a dose of the medication every single day. While the video game's ludic dimension centres on Chuck fighting off zombie hordes, its rather convoluted narrative boils down to a simple goal for Chuck: to keep his daughter from mutating. Chuck sports the chiselled physique of a stereotypical, manly Hollywood hero, which visually highlights the rampant protectionist paternalism at play in the game. Fittingly, in the closing minutes of the game, Chuck not only outsmarts thousands of undead and overcomes his main human adversary but also saves Katey and his girlfriend-to-be Stacey from certain death. In the end, the three walk away, holding hands, symbolising the re-establishment of the heteronormative nuclear family.

The game's hackneyed and overly clichéd finale confirms Eugène Provenzo's early observation that, in video games, male characters 'assume dominant gender roles' (1991, p. 100), while female characters are depicted as 'dependent or under control of another figure' (1991, p. 108). More recently, Leo Braudy has concluded that '[c]ultures and individuals hang on to outmoded styles of masculinity [...] built on simple masculine myths' $(2005$, p. 86), among which 'take control', 'be physically strong' and 'do not be afraid to kill' still play a key role (Walker, 2004, p. 4). Video games, in particular, continue to tap into this repertoire of traditional masculine positions. Indeed, a

cursory survey of the titles available in games stores, or a brief overview of the imagery, language, and implied readership of most popular video-game publications, reveals a masculinity that appears rooted in the traditional iconography of action, guns, and violence. (Kirkland, 2009, p. 165)

Similarly, Derek A. Burrill has argued that video games allow men to remain in eternal 'digital boyhood', a place that emerges from escapist fantasies and offers a safe haven against 'feminism, class imperatives, familial duties, as well as national and political responsibilities' (2008, p. 2).

However, in this contribution, we will suggest that the two titles discussed in the following - the first season of The Walking Dead (Telltale Games, 2012) and The Last of Us (Naughty Dog, 2013) significantly alter the 'uncompromisingly macho, triumphantly aggressive, and uncritical [...] expressions of masculinity' (Kirkland, 2009, p. 166) considered typical of video games. Part of the counter-hegemonic value of these two games lies in a gender ambiguity common in the horror genre. As Rhona J. Berenstein has argued, horror functions 'as a site of ideological contradiction and negation' (1996, p. 10). In particular, 'the figure of the monster' is 'fraught with ambiguities' in relation to 'historically constructed [...] gender attributes' (Berenstein, 1996, p. 29). Indeed, 
monstrosity is frequently 'defined in terms of gender deviance or sexual deviance from a hegemonic masculine ideal' (Rieser, 2001, p. 380). More importantly, perhaps, male characters in horror are recurrently emasculated through their encounter with, and subsequent fear of, deadly forces, and female protagonists often assume masculine traits when they come to face the monster (Clover, 1992). These transformations, ambiguities and contradictions make 'the genre [...] so troubling to conventional assumptions regarding gender' (Berenstein, 1996, p. 18).

Beyond these gender-bending conventions of their genre, The Walking Dead and The Last of Us are noteworthy for the particular masculine position of their primary player-characters - they are (surrogate) fathers. Throughout its history, the entertainment industry has been 'supportive of fathers', as 'it is a patriarchal institution and it respects the patriarch' (Bruzzi, 2005, p. xviii), but has rarely featured fathers as protagonists. Recently, however, as Hannah Hamad has pointed out, '[f]atherhood has become the dominant paradigm of masculinity' in the media (2014, p. 1). Whereas scholars such as Hamad see the role of the father almost universally imbricated in a 'conservative cultural logic of paternal protectionism' (Hamad, 2014, p. 55), we will highlight moments of resistance to these tendencies. To be sure, the two games analysed here partake in a deeply masculinist/patriarchal discourse, manifested, for example, in the obliteration of mothers and the attendant perpetuation of 'paternal protectionism.'

However, we would like to stress aspects which counter a totalising reading of these two games. After all, despite its alignment with patriarchy, (engaged) fatherhood is a liminal masculinity that fits uneasily in traditional conceptualisations of masculinity. For example, in the two games, the father figures, despite their aggressive acts (which are simultaneously demanded and sanctified by the survival narratives), are in tune with their feelings. They also nurture, listen to, and, ultimately, make way for their (surrogate) daughters. In other words, they exhibit traditionally feminine traits. Whereas scholars such as Hamad have suggested that 'postfeminist fatherhood props up the renegotiation of more traditional and conservative models of masculinity' (2014, p. 55), in this chapter, we will showcase some of the ways in which The Last of Us and The Walking Dead subvert (or at least question) the dominant fiction of paternal culture. Accordingly, we will suggest that in these two games, the father figures are not only protectors but also nurturers and that the daughter figures are not only symbols of vulnerability, but repeatedly assume control.

\section{Video Games and Gender}

Before moving on to the examination of the games, we need to briefly address two medium specificities of video games: the relationship between the player, the character and the avatar, on the one hand, and the connections between gameplay and gender, on the other. Put simply, avatars are the players' representatives in the gameworld. The underlying code of the game transforms players' inputs into actions in the virtual world, as it kinaesthetically maps the pushing of buttons, movement of the mouse, or, more recently, movement of the player's body onto the avatar. Consequently, the player experiences agency in the digital world, which facilitates both immersion in the gameworld and identification with the player-character. This strong connection between players and their virtual stand-ins bridges the difference between the real world and the gamespace. Jonathan Boulter has thus observed that 'when I am alone with my game console, [...] I assume the role, the identity of the avatar', as '[t]he avatar [...] extends my identity and my space' $(2015$, p. 8). The avatar allows players to extend their bodies into the game space from the physical space outside, since it remediates the player's agency in the virtual world. The avatar thus 'becomes [...] part of the player's "I can"', as '[t]he player is [...] re-wired and re-directed [...] through the 
integrated prosthetic apparatus of controller and [...] avatar' (Klevjer, 2012, pp. 27-28). As a result, players interact not only with the virtual environment, but, more importantly, also their avatars. While playing, the player thus exists 'as a composite of flesh and technology' (Klevjer, 2012, p. 34), thereby becoming 'more'-than-human.

In this way, video game avatars may epitomise post- and transhuman utopian fantasies, as avatars 'allow players to loosen the ties to their molar identities' and liberate themselves from the 'rigid categories of class, race, gender, and species structured by unequal power relations' (Fuchs, forthcoming). Consequently, similar to the ways in which post- and transhumanism have embraced emerging technologies, scholars such as James Newman have celebrated the purported genderblindness of video games. Players - if given the choice between gendered characters - would not focus on the character's gender, but rather on 'game-play-affecting characteristics', such as certain powers or abilities, he has suggested (2013, p. 125). Indeed, Newman has even stated that since 'the pleasures of video game play are not principally visual, but rather [...] kinaesthetic' (2002, para 5; italics in original), the visual representation of a character is irrelevant (2002). However, this optimistic appraisal of technology is far from undisputed. Rather than obliterating gender, digital technology arguably reinforces gender and other social hierarchies, since 'technology [...] fundamentally embodies a culture or set of social relations made up of certain sorts of knowledge, beliefs, desires, and practices' (Wajcman, 1991, p. 149). Indeed, the visual representation of avatars and non-playing characters influences and is influenced by heteronormative gender norms; this 'set of repeated acts within a highly rigid regulatory frame that congeal over time to produce' (Butler, 1990, p. 33) what Michel Foucault called 'docile bodies' (1995, pp. 135-169). In the following, we argue that the visual representation of gender does matter in The Last of Us and The Walking Dead. It matters that the surrogate daughter figure in The Last of Us, Ellie, is a visual reminder of the spectral presence of another young girl; it matters that Lee, the main character - and main avatar in The Walking Dead is an African American man; and it matters that neither of the girls in the two games is visually sexualised.

Moreover, gameplay as such is also gendered. As Justine Cassell and Henry Jenkins have highlighted, two core elements of gameplay are culturally coded as masculine: 'violent action' and the 'exploration of space' (1998, p. 8). While the masculine dimensions of the former should need no further explanation, Jenkins elaborates on the latter in another piece, co-written with Mary Fuller: 'Virtual reality opens new spaces for exploration, colonisation, and exploitation, returning to a mythic time when there were worlds without limits and resources beyond imagining' (1995, p. 58). Moreover, according to Jenkins and Fuller, at the heart of the pleasure of playing video games 'is the promise of [...] mastering these worlds and making them your own playground' $(1995$, p. 62) - both masculinised actions. Other scholars have, however, stressed that this mastery is always-already an illusion. In his elaborations on play, Hans-Georg Gadamer points out that 'all playing is a beingplayed. The attraction of a game [...] consists precisely in the fact that the game masters the players' (2004, p. 160). Expanding on this premise, Riccardo Fassone has stressed that games tend to open up questions concerning 'the very notion of authority' $(2015$, p. 49), as they constantly simultaneously create the illusion of player agency in the virtual world and - implicitly or explicitly confront players with how little they, in fact, control the game.

This oscillation between the illusion of control and the lack thereof, which actually reinforces players' complicity with the hegemonic ideal, becomes particularly prevalent in horror games. Tellingly, Geoff King and Tanya Krzywinska have concluded that 'with sufficient honing of skills', players may master 'the threat [...] through their own activity' $(2006$, p. 216). This mastery, they continue, 'might [...] be understood as a reassertion of masculine identity [...] at the level of mastery 
of the game' (2006, p. 216). However, horror games repeatedly make players' lack of agency explicit. Indeed, the genre is characterised by 'a dynamic rhythm between selfdetermination and predetermination' (Krzywinska, 2002, p. 207). These seesaw changes are often caused by the 'constant alternation between gameplay and cinematics', which 'effects a near endless oscillation between moments in which players are in control and moments in which they are not in control' (Fuchs, 2016, p. 43) - moments between a rather masculine and a rather feminine position, respectively. While both The Last of Us and The Walking Dead employ pre-rendered sequences to the same effect, these games undercut rigid gender binaries in other ways, as well.

\section{Fetishising the Child, Paternalism and the Player-Character Divide in The Last of Us}

The Last of Us opens in present-day Texas. Single father Joel comes home from work just a few minutes before midnight but still in time for his daughter Sarah to surprise him with a birthday gift. While Joel's life as a single father seems arduous, Sarah appears satisfied and their family life stable. However, in the same night, nearby explosions interrupt this picture of domestic wholesomeness, as Sarah is startled awake. When the opening cinematic gives way to gameplay, players first control Sarah, who is looking for her dad. Joel, however, is nowhere to be seen until he suddenly bursts through the veranda door, chased by a disfigured creature - their neighbour. As the opening credits clarify a little later, a mutant Cordyceps fungus, which transforms its human hosts into creatures yearning human flesh (simply referred to as 'Infected'), has just broken out and begins to ravage the United States. Joel (now the player's avatar), his brother Tom and Sarah try to escape the initial public disorder, but a soldier shoots Sarah in the chaos, and she dies in Joel's arms. Twenty years later, the infection has effectively ruined the United States. Most survivors live in military quarantine zones in former metropolitan areas, as nomad groups roaming cities and their surroundings, or in independent fortified rural settlements. Joel lives in the Boston quarantine zone, where he takes on various illegal jobs. One day, he and his friend Tess are asked to smuggle a very special 'cargo' out of Boston: fourteen-year-old Ellie. As it turns out, Ellie was bitten three weeks prior. While, normally, the mutation occurs less than two days after contact, she is still healthy. Ellie thus emerges as humanity's hope for a cure. In the course of the game, covering a whole year, Joel does everything humanly possible to ensure Ellie's survival, as the two travel through the United States, moving westward from Boston to Salt Lake City (and then back to Wyoming).

Ellie at first represents the prototypical vulnerable child in need of protection and mankind's hope for the future. Especially in the opening hours of the game, Joel must protect this potential more so than Ellie the person. In his highly polemical book No Future (2004), Lee Edelman claims that at the heart of many American values resides a 'focus on the protection of children' (2004, p. 1). This focus, he continues, emerges from 'the social consensus that [...] an appeal [on the behalf of America's children] is impossible to refuse' $(2004$, p. 2). The 'innocence [of the Child] solicits our defense' (2004, p. 2), for to fight for 'our' children is to fight for 'our' future - and thus to fight for heteronormativity, as the discourse of the child creates a decidedly regressive (and oppressive) social order that seeks 'to affirm a structure, to authenticate social order' (2004, p. 3; emphasis in original) that is eternally locked in 'the impossible place of an Imaginary past' (2004, p. 10).

Hamad has pointed out that this 'logic of paternal protectionism' draws on the tradition of the captivity narrative, which 'provided a pernicious and efficacious ideologically charged means' for popular culture to 'cast emblematic white male paternal figures as heroic rescuers of imperiled girls and young women' $(2014$, p. 66). This narrative blueprint relies on simultaneously overdrawn and incrusted Manichean binaries, as every character 'is either a dangerous Other (in terms of race 
and/or class), or a victim of these dangerous Others' (Hamad, 2014, p. 66). According to Kathleen Karlyn, popular culture texts tend to celebrate these retrogressive ideas and thereby 'justif[y] (white) male violence by invoking the need to protect women and children from (dark) outsiders' (2011, p. 100). This narrative 'requires that women be unable to defend themselves', for they 'must be weak to justify male aggression and allow men to be men' (Karlyn, 2011, p. 100).

At first, The Last of Us seems to adhere to this regressive politics entailed by the fetishisation of the child. However, the game complicates heteronormative gendering. While Joel initially considers Ellie just another 'package' and emphasizes at one point that Ellie is 'not [his] daughter, and [he] sure as hell ain't [her] dad' (Naughty Dog, 2014), their relationship clearly evolves as they travel across the United States. In the early stages of the game, this relationship is defined by Joel's paternalism: he doesn't want Ellie to carry weapons and requires her to remain by his side at any given moment. Joel's paternalism proves problematic, for even though he mostly acts in Ellie's best interests (or, rather, what he believes to be her best interests), he also interferes in her autonomy. As a result, Joel restricts Ellie's freedom and ensures his dominant role in their relationship. However, since Ellie, as a typical teenager, repeatedly tests her boundaries, she constantly challenges Joel's authoritative role.

This dialogic of power culminates in the final quarter of the game when Joel is severely injured. First, players are still tied to Joel as their avatar, who is wounded and can barely move, and thus have to rely on Ellie to take out the remaining bandits. When Joel passes out, Ellie becomes the players' avatar, goes hunting in the woods and procures antibiotics in order to treat Joel's wounds. When some time later, a group of cannibals captures Ellie, she again seems to turn into the typical 'damsel in distress' who requires Joel (and the player) to save her from being raped and turned into food. However, here, the video game's interference with the operating principles of the captivity narrative becomes most explicit, as players alternately control Joel and Ellie. Joel makes his way to Ellie, while Ellie frees herself and takes revenge on the men who captured her. Indeed, by the time Joel reaches Ellie, she has killed several cannibals, including their leader, thereby making explicit that despite her fragile looks, she can take care of herself. Consequently, neither is Ellie the helpless female (and feminine) victim nor is Joel the male (and masculine) hero - rather, the two are mutually codependent. In fact, the game's conclusion implies that Joel needs Ellie more than she needs him.

When the two finally reach their intended destination, Joel is shocked to hear that to distil a cure, Ellie would have to die. While Ellie's old friend and mother figure Marlene wants to sacrifice the girl for humanity's future, Joel, unwilling to lose a second daughter, kills the doctors and Marlene. Players have no choice here - they have to kill the doctors if they want to complete the game. Whereas players might be willing to sacrifice Ellie in order to (possibly) save humankind, Joel clearly is not. In these moments, The Last of Us emasculates players. While, until this point, the game creates the illusion that players are active and in control of Joel (and, thus, in control of how the entire narrative unfolds), they have no influence on the final outcome whatsoever. They become passive witnesses to the unfolding drama, as narrative trumps interactivity in this meta-ludic gesture, which 'reinforces the sense that a metaphysical 'authorial' force is at work, shaping the logic of the game' (Krzywinska, 2002, p. 207).

The creative decision to relieve players of control at the end of the game not only underlines the game's narrative drive but also stresses the weight of Joel's choice. He prioritises his own interests not losing his daughter and not being alone - over those of humankind at large and denies Ellie the sacrificial death, which is one of the classical paths for heroes. However, the relation between Joel and Ellie is more ambivalent: in a way, Joel does exactly what Ellie wants, the narrative suggests. Indeed, throughout the game, Ellie admires nature, from which she was secluded in the urban 
quarantine zone she grew up in. When Ellie and Joel see giraffes grazing in the middle of Salt Lake City, they seem to share an unspoken understanding that 'a more meaningful life is possible closer to nature beyond the constraining, complex, and corrupt city' (Machor, 1987, p. 3). Clearly, saving Ellie without asking her opinion is a paternalistic move, but one that gives the non-human world a chance in its battle with humans.

Moreover, Ellie's survival disengages from the heteronormative discourse about the child-as-future, as some of her traits and actions connote lesbianism. Ellie's lesbian identity subverts the procreative principle of heteronormative society; instead, Ellie represents a queer utopianism. José Esteban Muñoz has argued that '[q]ueerness is essentially about the rejection of a here and now and an insistence on potentiality or concrete possibility for another world' $(2011$, p. 1). Importantly, if there is a human future in The Last of Us, that future has a single name - Ellie. The video game thus consciously adds a queer/feminist spin to a tried-and-true science fiction formula. The Last of Us is not the masculine narrative played out in films such as The Last Man on Earth (1964) and I Am Legend (2007), but rather a swan song to male-dominated society. Significantly, as a lesbian character, not only ends patriarchy, but rather emerges as a truly 'final girl' - the harbinger of the end of humankind. Apparently, the game can envision an end to patriarchal and heteronormative society only concomitant with an end of the world as we know it.

\section{Violence and Sacrificial Fatherhood in The Walking Dead: Season One}

While Joel in The Last of Us is a complex, but clearly paternalistic, hero, the protagonist of The Walking Dead: Season One emerges as a very different type of character. The Walking Dead puts players in control of Lee Everett, an African American who used to teach history at the University of Georgia, but was found guilty of the murder of his ex-wife's lover. As the action starts, Lee is sitting on the backseat of a police cruiser, leaving Atlanta on his way to prison. Accordingly, players first meet their avatar handcuffed in a police car, in a powerless, emasculated position vis-à-vis the patriarchal power of the authorities. Suddenly, a zombie appears on the highway, causing the police car to crash. As Lee thus regains his freedom, he finds the area infested with zombies. Indeed, the zombie outbreak has quickly turned the world into a life-threatening post-apocalyptic landscape. While the world around Lee is transforming, he has no influence on said changes. This powerlessness in the face of grave danger has been characteristic of horror since the 1960s, as Robin Wood has noted: '[A]nnihilation is inevitable, humanity is now completely powerless, no one can do anything to arrest the process' (1986, p. 88). Soon, Lee encounters eight-year-old Clementine, whose parents are away on a trip to Savannah and whose babysitter has turned into a zombie. Almost from the moment Lee meets Clem, his prime task becomes to protect her. Slaughtering zombies in selfdefence, choosing the best way for survival, maintaining safe and - whenever possible - amiable relationships with other survivors and other challenges make up the tasks the game sets for the player, but are all subordinated to protecting and saving Clem.

The gameplay of The Walking Dead consists of three core elements: (1) walking around, (2) interacting with objects and (3) dialogues. The final element takes on particular significance in The Walking Dead, in general, and its depiction of fatherhood, in particular. Linguist J. L. Austin has famously argued that ' $[t]$ he issuing of the utterance is the performing of an action' $(1975$, p. 6). Accordingly, players perform Lee's masculinity and his role as Clementine's surrogate father through these dialogue choices. Players may opt to repeatedly lie to Clementine, neglect her or confront her with the realities of living in a world in which zombies rule. In this way, these performative acts define Lee's gender characteristics and his relationship with Clementine. 
The significance of players' dialogue choices culminates in the game's finale. Clementine has disappeared. When Lee finally comes to understand that she was, in fact, not attacked by a zombie, but rather kidnapped by a human being, a zombie bites him. The final episode reveals the kidnapper to be a psychotic stranger, whose car was looted by the group Lee and Clem journeyed with. Irrespective of whether Lee, earlier in the game, joined the group in plundering the car, the stranger accuses Lee of causing his family's death. The stranger goes on to confront Lee - and the playerwith some of their decisions, primarily those related to violence (most of which Clem, whose age allows her to have a naïve and idealised worldview, criticised earlier in the game). The conversation with the kidnapper forces Lee and the player to reflect on their past actions, along with their consequences, potential alternatives and how these actions have informed others' (in particular, Clem's) ideas of what kind of a man Lee is. Although Clementine's kidnapper lost his wife and daughter in the zombiecalypse, he is firmly convinced that he 'can take care of [Clementine]' and 'be a dad' (again). Conversely, he accuses Lee of having failed as a father, since Lee 'walked a little girl into a dairy full of sick people and let them get their hands on her' and 'brought her to the most dangerous place in [Savannah] where she could've died' (Telltale Games, 2012). This encounter is resolved when Clem sneaks up behind the kidnapper and whacks him. Consequently, either Lee strangles the stranger or Clem shoots him. Overall, this lengthy scene plays a key role in The Walking Dead's narrative, as it asks players to reflect on what masculinity means and what being a father entails - all vis-à-vis a girl who becomes the implicit arbiter of the player's choices.

However, the confrontation with the stranger is just the beginning of the concluding drama, as Lee's zombie bite takes its toll. In the moment when the zombie bites Lee, the creature's teeth penetrate the man's skin and thus feminise his body, which quickly begins to rot. As Lee's body decomposes, it is increasingly turned into a visual spectacle. In the final minutes of the game, Lee's body is immobilised to such a degree that he needs Clementine to act in his place, thereby surrendering the active, male role to the young girl. In this meta-ludic moment, Lee's immobile and physically confined body mirrors the players sitting in front of their screens, while Clementine effectively functions as Lee's avatar, thus anticipating that Clementine will become the user-character in the second season.

As his life is about to end, Lee faces a final decision. Trapped in a warehouse with Clem, surrounded by hundreds of zombies, and taking his last breaths, he can either ask Clem to leave him behind or to kill him. The players' performative choice thus plays out two different kinds of liminal masculinity: sacrifice or ceding control to Clem. By asking Clem to leave, he both shields her from the horrifying experience of killing someone she is close to and sacrifices himself. Sacrifice, Kaja Silverman has argued, 'has radically emasculating implications [...] and is [...] intrinsically incompatible with the pretensions of masculinity' (1992, p. 198). This emasculation is highlighted by the visual spectacle of Lee's decomposing body. Irrespective of whether players choose to amputate Lee's bitten arm, which slows down putrefaction, Lee's body slowly rots in the last two hours of the game (depending on how fast players proceed), as Lee increasingly incapacitates. Since the decomposition of Lee's body is unchangeable, players are forced to come to terms with his emasculation incrementally, both on the representational and the ludic level.

Lee's ceding of control becomes particularly prevalent in the alternative option in the final scene, as he may ask Clementine to shoot him in the head. 'The moment of separation from hegemonic masculinity' here clearly 'involves choosing passivity' (Connell, 1995, p. 132). Thus, Lee is simultaneously emasculated and redeemed through Clem's murder, as the act paradoxically codes him as a valuable surrogate father: The surrogate daughter kills the surrogate father in what may be described as a post-Oedipal scenario, as Clem is ready to step into her (surrogate) father's place the 
moment he is dead. In this way, Lee's death represents the only 'possible strategic outlet from dominant masculinity' (Rieser, 2006, p. 172); the only way for Clem to take over control - and to become the avatar in season two.

\section{Fatherhood in Post-Apocalyptic Horror Games}

The two video games discussed above relate masculinist narratives: mothers are absent, the main avatars are male, the characters in need of protection are vulnerable, young and desexualised girls, and the zombiecalypse setting reinforces the violent paternal rescue scenario. Indeed, one could easily argue that the father figures controlled in these games highlight that '[p]atriarchal societies are male identified in that core cultural ideas about what is considered good, desirable, preferable, or normal are associated with how we think about men and masculinity' (Johnson, 2005, p. 6).

However, the two games complicate matters in various ways: in The Last of Us, the constant dialogic of power between the two main characters renders it impossible to label Joel the dominant one in their relationship. This back-and forth in terms of power is echoed in the gameplay, as players alternatingly control the father and daughter figures. Furthermore, Ellie's lesbianism highlights her continuous performance of 'female masculinity' (Halberstam, 1998). In The Walking Dead, Lee is increasingly emasculated due to his rotting body, to the point that his death signals the end of hegemonic masculinity.

Indeed, whereas scholars such as Hamad have suggested that especially disaster and apocalypse narratives perpetuate a 'conservative cultural logic of paternal protectionism' (2014, p. 55), in these two video games, the father is progressively divested of the protector's role and the daughter assumes control. This aspect becomes particularly apparent in the games' endings. While both endings signal a lack of assuredness, which results from the collapse of long-established cultural norms and givens, both games embrace endings in which the father figure is either already dead (The Walking Dead) or dead sooner rather than later (The Last of Us). In both cases, these individual deaths represent the death of patriarchal culture on a much larger scale. In these games, the era of the (heteronormative) dad has come to an end.

\section{References}

Austin, J. L. (1975). How to do things with words. Oxford: Clarendon.

Berenstein, R. J. (1996). Attack of the leading ladies: Gender, sexuality, and spectatorship in classic horror cinema. New York, NY: Columbia University Press.

Blue Castle Games (2010). Dead Rising 2. Capcom. Xbox 360.

Boulter, J. (2015). Parables of the posthuman: Digital realities, gaming, and the player experience. Detroit, MI: Wayne State University Press.

Braudy, L. (2005). From chivalry to terrorism: War and the changing nature of masculinity. New York, NY: Vintage.

Bruzzi, S. (2005). Bringing up daddy: Fatherhood and masculinity in post-war Hollywood. London: BFI.

Burrill, D. A. (2008). Die Tryin': Videogames, masculinity, culture. New York, NY: Peter Lang. 
Butler, J. (1990). Gender trouble: Feminism and the subversion of identity. London: Routledge.

Cassell, J., \& Jenkins, H. (1998). Chess for girls? Feminism and computer games. In J. Cassell \& H. Jenkins (Eds.), From Barbie to Mortal Kombat: Gender and computer games (pp. 2-45). Cambridge, MA: MIT Press.

Clover, C. J. (1992). Men, women, and chainsaws: Gender in the modern horror film. Princeton, NJ: Princeton University Press.

Connell, R. W. (1995). Masculinities. Berkeley, CA: University of California Press.

Edelman, L. (2004). No future: Queer theory and the death drive. Durham, NC: Duke University Press.

Fassone, R. (2015). This is video game play: Video games, authority and metacommunication. Comunicação e Sociedade, 27, 37-52.

Foucault, M. (1995). Discipline and punish: The birth of the prison (Alan Sheridan, Trans.). New York, NY: Vintage.

Fuchs, M. (forthcoming). Playing (with) the nonhuman: Video games and animal avatars. In C. Mengozzi (Ed.), Outside the anthropological machine: Crossing the human-animal divide and other exit strategies. London: Routledge.

Fuchs, M. (2016). A different kind of monster: Uncanny media and Alan Wake's textual monstrosity. In C. Duret \& C.-M. Pons (Eds.), Contemporary research on intertextuality in video games (pp. 39-53). Hershey, PA: IGI Global.

Fuller, M., \& Jenkins, H. (1995). Nintendo and new-world travel writing: A dialogue. In S. G. Jones (Ed.), Cybersociety: Computer-mediated communication and community (pp. 57-72). Thousand Oaks, CA: Sage Publication.

Gadamer, H.-G. (2004). Truth and method. London: Continuum.

Halberstam, J. (1998). Female masculinity. Durham, NC: Duke University Press.

Hamad, H. (2014). Postfeminism and paternity in contemporary U.S. film: Framing fatherhood. New York, NY: Routledge.

Johnson, A. G. (2005). The Gender knot: Unravelling our patriarchal legacy. Philadelphia, PA: Temple University Press.

Karlyn, K. R. (2011). Unruly girls, unrepentant mothers: Redefining feminism on screen. Austin, TX: University of Texas Press.

King, G., \& Krzywinska, T. (2006). Tomb raiders and space invaders: Videogame forms and contexts. London: I. B. Tauris.

Kirkland, E. (2009). Masculinity in video games: The gendered gameplay of Silent Hill. Camera Obscura, 24(2), 161-183.

Klevjer, R. (2012). Enter the avatar: The phenomenology of prosthetic telepresence in computer games. In H. Fossheim, T. M. Larsen, \& J. R. Sageng (Eds.), The philosophy of computer games (pp. 17-38). Leiden: Springer.

Krzywinska, T. (2002). Hand-on horror. In G. King \& T. Krzywinska (Eds.), Screenplay: Cinema/videogames/interfaces (pp. 206-223). London: Wallflower. 
Machor, J. L. (1987). Pastoral cities: Urban ideals and the symbolic landscape of America. Madison, WI: University of Wisconsin Press.

Muñoz, J. E. (2011). Cruising utopia: The then and there of queer futurity. New York, NY: New York University Press.

Naughty Dog (2014). The Last of Us: Remastered. Sony Computer Entertainment. PlayStation 4.

Newman, J. (2013). Videogames (2nd ed.). Abingdon: Routledge.

Provenzo, E. F. (1991). Video kids: Making sense of Nintendo. Cambridge, MA: Harvard University Press.

Rieser, K. (2001). Masculinity and monstrosity: Characterization and identification in the slasher film. Men and Masculinities, 3(4), 370-392.

Rieser, K. (2006). Borderlines and passages: Liminal masculinities in Film. Essen: Die Blaue Eule.

Silverman, K. (1992). Male subjectivities at the margins. New York, NY: Routledge.

Telltale Games (2012). The Walking Dead: A Telltale Game Series. Season 1. Telltale Games.

Wajcman, J. (1991). Feminism confronts technology. University Park, PA: Pennsylvania State University Press.

Walker, R. (2004). Putting down the gun. In R. Walker (Ed.), What makes a man? 22 writers imagine the future (pp. 1-7). New York, NY: Riverhead.

Wood, R. (1986). Hollywood from Vietnam to Reagan. New York, NY: Columbia University Press. 